Review

\title{
Total Occlusal Convergence and Margin Design in Relation to Survival of Glass-Ceramic Crowns: A Review
}

\author{
${ }^{1}$ Janine Tiu, ${ }^{1}$ J. Neil Waddell, ${ }^{1}$ Basil Al-Amleh and ${ }^{2}$ Michael V. Swain \\ ${ }^{I}$ Sir John Walsh Research Institute, Faculty of Dentistry, University of Otago, Dunedin, New Zealand \\ ${ }^{2}$ Biomaterials Laboratory, University of Sydney, Sydney, Australia
}

\author{
Article history \\ Received: 15-08-2014 \\ Revised: 05-09-2014 \\ Accepted: 14-1-2015 \\ Corresponding Author: \\ Janine Tiu \\ Sir John Walsh Research \\ Institute, Faculty of Dentistry, \\ University of Otago, \\ Dunedin, New Zealand \\ Email: janine.tiu@gmail.com
}

\begin{abstract}
This review aims to report on preparation geometry parameters and their relation to crown failures in complete glass-ceramic clinical studies. A review of the literature was conducted in MEDLINE/PubMed with an additional manual search. The articles were screened through an inclusion and exclusion criteria and information regarding the Total Occlusal Convergence (TOC) angle and margin design was extracted along with its survivability. Nineteen articles were found, three were retrospective studies and 16 were prospective. Three articles specified TOC and 16 articles specified their margin design. Eighty failures were reported but lack of information between core and margin design and failures meant the relationship was inconclusive. There were a limited number of long-term clinical studies assessing glass-ceramic complete crowns. These studies provided insufficient information regarding the TOC angles of the prepared crowns and its potential effect on the survivability of glass-ceramic crowns. Further studies need to be conducted to determine how the TOC and margin design can affect the survival rates of glass-ceramic complete crowns.
\end{abstract}

Keywords: Glass-Ceramic, Total Occlusal Convergence, Survival, Margin Design, Review

\section{Introduction}

There is a growing interest and demand for allceramic materials as single crown restorations. Underlying the crown are the fundamental foundations of tooth preparation principles which aim to maximise the retention and resistance and in turn, the survivability of the resulting crown. The retention prevents the dislodgment of the restoration by forces parallel to the path of insertion and resistance prevents the dislodgement of the restoration by oblique and occlusal forces (GPT, 2005).

Restorations are exposed to a range of masticatory forces in the oral environment and as a result, restoration fractures and crown loosening are common failures observed (Walton et al., 1986; Wiskott et al., 1996; Pjetursson et al., 2012). Such failures are often attributed many factors including the retention and resistance factors of the system.

The governing geometric parameters contributing the retention and resistance in a preparation is namely the Total Occlusal Convergence (TOC) angle, the margin design and the abutment height. The recommendations for these parameters have somewhat remained unchanged from conventional metal and metal-ceramic crowns. The TOC is recommended to be as small as possible and the abutment height is recommended to be as tall as possible (with enough spacing for the restoration).

The TOC angle is the sum angle of the two opposing axial walls in the preparation. This geometric feature has been long and extensively studied in the literature with early laboratory studies. Prothero (1923) indicating a convergence angle range of $2-5^{\circ} \mathrm{C}$, Jorgensen (1955) experimentally found maximum tensile retention at $5^{\circ} \mathrm{C}$ and many others (Kaufman et al., 1961; Tylman, 1965; El-Ebrashi et al., 1969) all recommending similar TOC values. Later, clinical studies proved this minimal TOC angle was hard to achieve (Eames et al., 1978; Mack, 1980; Owen, 1986). Ohm and Silness (1978) tested dentistry students in their final year and found the TOC angles for vital teeth ranged from $19^{\circ} \mathrm{C}$ to $27^{\circ} \mathrm{C}$. Other studies testing students and practitioners (Leempoel et al., 1987; Nordlander et al., 1988; Noonan and Goldfogel, 1991; Annerstedt et al., 1996; Ayad et al., 2005) all reported higher convergence angles showing discrepancies between recommended and actual values carried out in practice.

The margin design is the only parameter which is material dependent as it directly affects the shape and 
amount of bulk material. Early designs were based on requirements for complete metal or metal-ceramic crown restorative materials. The malleable property of the metal, especially noble alloys meant the margin designs were more forgiving. An excellent fit could be achieved by burnishing down the material to the finish line with thin feather-edge or bevel-edge margins (McLean et al., 1979). Although feather-edge designs have been used with stronger and tougher zirconia crowns (Schmitt et al., 2010), glass-ceramic restorations require thicker margins and only specific shaped chamfers and shoulders are indicated (Rosenstiel et al., 2006). Gavelis et al. (1981) found a $90^{\circ}$ shoulder margin had the best seating. Theoretically, for glass-ceramic restorations any deviations from the chamfers and shoulders to bevel-like margins would compromise the structural integrity and introduce uneven force distribution when axially loaded, which could lead to a weaker structure and ultimately failure originating from the margin. The manufacturer suggests a margin width of at least 1.0-1.5 mm with smooth internal lines to reduce potential for crack propagation.

Survivability of crowns cannot be exclusively attributed to a single factor as the factors affecting the survivability of glass-ceramic single crowns are multifaceted. It is suggested that core design plays an important role in survivability, although the extent of this is still unknown (Goodacre et al., 2001; Rekow et al., 2011). Preparation geometry parameters have been universally accepted as factors that affect retention and resistance and may contribute to the clinical longevity of a single crown. This review aims to report on preparation geometry parameters and their relation to crown failures in complete glass-ceramic clinical studies.

\section{Materials and Methods}

An electronic search of MEDLINE and PubMed was conducted in February 2013 to identify the clinical performance of glass-ceramic crowns in relation to the TOC and margin design published between 1986 and January 2013 with the following expanded search terms:

$$
\begin{aligned}
& \text { "glass ceramic" AND "margin design" } \\
& \text { "glass ceramic" AND "crown preparations" } \\
& \text { "glass ceramic" AND "margin failure" }
\end{aligned}
$$

An additional manual search was conducted through the literature to identify clinical trials that may not have been listed on MEDLINE/PubMed. The articles were chosen according to the inclusion and exclusion criteria in Table 1.
Table 1. Inclusion and exclusion criteria

\begin{tabular}{ll}
\hline Inclusion criteria & Exclusion criteria \\
\hline English language & Case reports, in vivo studies \\
Prospective or retrospective & Studies only on PFM, metals, \\
clinical study focused & inlays, onlays, veneers, partial \\
on all-ceramic crowns & $\begin{array}{l}\text { crowns, bridges, Fixed Partial } \\
\text { Dentures (FPD) }\end{array}$ \\
Studies using leucite & Animal studies \\
or lithium disilicate & \\
ceramic reinforced & \\
\hline
\end{tabular}

The keyword search yielded an accumulative 483 articles from which titles, abstract and some full texts were screened according to the inclusion and exclusion criteria in Table 1. Seventeen articles were chosen and a further manual search was conducted on the references of these articles to identify any other articles that did not turn up on the initial MEDLINE/PubMed search. From this a further two articles were found bringing the combined total to 19 articles chosen.

Failure rate was calculated by dividing the total number of failed crowns by the total crown exposure time in years. A 95\% Confidence Interval (CI) was calculated for the failure rate. A five year projection was made by multiplying the failure rate by five.

\section{Results}

This review shows the current published clinical studies of glass-ceramic complete crowns (leucite and lithium disilicate reinforced) report a $92 \%$ or higher survivability. There were 16 prospective studies and three retrospective studies. The total number of crowns was 2095 from cumulative data reported from all 19 studies. There were 1082 anterior teeth and 1013 posterior teeth. Three clinical studies reported a range of TOC angles (Fradeani and Aquilano, 1997; Fradeani and Redemagni, 2002; Gehrt et al., 2013) while most articles specified the margin design used except for two articles (Sjogren et al., 1999; Mansour et al., 2008) and one stated "manufacturer's instructions" (Reich et al., 2010) (Table 2).

\section{Failures}

Consolidating the data from all clinical studies included in this review, glass-ceramic complete crowns had a failure rate of $1.10 \%(95 \% \mathrm{CI}=1.097-1.102 \%)$. This equates to a projected 5 year failure rate of $5.49 \%$. The anterior failure rate was $0.96 \%$ and posterior failure rate was $1.25 \%$.

Removing studies with mean follow up values of less than 36 (months), the glass-ceramic complete crowns had a failure rate of $0.84 \%(95 \% \mathrm{CI}=0.75-0.93 \%)$. The revised failure rates were 0.71 and $0.99 \%$ for anterior and posterior respectively $(\mathrm{P}=0.30)$.

Common modes of failure include fracture, core fractures, break in cement, de-cementation and chipping. 


\begin{tabular}{|c|c|c|c|c|c|c|c|c|c|c|}
\hline Material & Study & Year & Survivability & $\begin{array}{l}\text { Mean } \\
\text { follow up } \\
\text { (months) }\end{array}$ & $\begin{array}{l}\text { No. of } \\
\text { crowns }\end{array}$ & Anterior & Posterior & $\begin{array}{l}\text { Period } \\
\text { (years) }\end{array}$ & $\begin{array}{l}\text { Total occlusal } \\
\text { convergence }\end{array}$ & $\begin{array}{l}\text { Margin } \\
\text { design }\end{array}$ \\
\hline \multirow[t]{8}{*}{ IPS empress } & Malament et al. (2003) & 2003 & $99.90 \%$ & 60.00 & 607.00 & 358.00 & 249.00 & 10.40 & & Chamfer/shoulder $1.2-1.5 \mathrm{~mm}$ \\
\hline & Sorensen et al. (1998) & 1998 & $99.00 \%$ & 36.00 & 75.00 & 47.00 & 28.00 & 3.00 & & Shoulder \\
\hline & Fradeani and Aquilano (1997) & 1997 & $99.00 \%$ & 37.00 & 144.00 & 101.00 & 43.00 & 3.00 & $5-10$ & $90^{\circ}$ shoulder $1.2-1.5 \mathrm{~mm}$ \\
\hline & Fradeani and Redemagni (2002) & 2002 & $95.20 \%$ & 78.00 & 125.00 & 93.00 & 32.00 & 11.00 & $5-10$ & $90^{\circ}$ shoulder $1.2-1.5 \mathrm{~mm}$ \\
\hline & Studer et al. (1998) & 1998 & $95.00 \%$ & 61.00 & 142.00 & 67.00 & 75.00 & 2.00 & & $90^{\circ}$ shoulder \\
\hline & Lehner et al. (1997) & 1997 & $95.00 \%$ & 20.00 & 78.00 & 41.00 & 37.00 & 2.00 & & $90^{\circ}$ shoulder $1.0-1.2 \mathrm{~mm}$ \\
\hline & Gemalmaz and Ergin (2002) & 2002 & $94-95 \%$ & 24.50 & 37.00 & 21.00 & 16.00 & 2.00 & & Shoulder $1.2-1.5 \mathrm{~mm}$ \\
\hline & Sjogren et al. (1999) & 1999 & $92.00 \%$ & 43.20 & 110.00 & 43.00 & 67.00 & 3.50 & & \\
\hline \multirow[t]{6}{*}{ IPS empress II } & Suputtamongkol et al. (2008) & 2008 & $100.00 \%$ & 12.00 & 30.00 & 0.00 & 30.00 & 1.00 & & Shoulder/chamfer $1 \mathrm{~mm}$ \\
\hline & Marquardt and Strub (2006) & 2006 & $100.00 \%$ & 60.00 & 27.00 & 0.00 & 27.00 & 5.00 & & Chamfer $1.2 \mathrm{~mm}$ \\
\hline & Taskonak and Sertgoz (2006) & 2006 & $100.00 \%$ & 24.00 & 20.00 & 12.00 & 8.00 & 2.00 & & Shoulder $1.5 \mathrm{~mm}$ \\
\hline & Valenti and Valenti (2009) & 2009 & $95.50 \%$ & 59.00 & 261.00 & 101.00 & 160.00 & 10.00 & & $90^{\circ}$ shoulder \\
\hline & Toksavul and Toman (2007) & 2007 & $95.00 \%$ & 58.00 & 79.00 & 56.00 & 23.00 & 5.00 & & Shoulder $1-1.3 \mathrm{~mm}$ \\
\hline & Mansour et al. (2008) & 2008 & $93.90 \%$ & 25.30 & 82.00 & 60.00 & 22.00 & 1.50 & & \\
\hline \multirow[t]{3}{*}{ IPS e.max CAD } & Fasbinder et al. (2010) & 2010 & $100.00 \%$ & 14.00 & 62.00 & 0.00 & 62.00 & 2.00 & & Shoulder \\
\hline & Reich et al. (2010) & 2010 & $97.40 \%$ & 14.00 & 41.00 & 0.00 & 41.00 & 2.00 & & Manufacturer's instructions \\
\hline & Reich and Schierz (2013) & 2012 & $96.30 \%$ & 51.00 & 41.00 & 0.00 & 41.00 & 4.60 & & Shoulder/chamfer $1 \mathrm{~mm}$ \\
\hline \multirow{7}{*}{ IPS e.max press } & Etman and Woolford (2010) & 2010 & $96.60 \%$ & 36.00 & 30.00 & 0.00 & 30.00 & 3.00 & & Chamfer $0.8-1 \mathrm{~mm}$ \\
\hline & Gehrt et al. (2013) & 2013 & $94.80 \%$ & 79.50 & 104.00 & 82.00 & 22.00 & 8.00 & $6-15$ & Shoulder/chamfer $1 \mathrm{~mm}$ \\
\hline & Mean & & $96.92 \%$ & 41.71 & 110.26 & 60.12 & 55.88 & 3.92 & & \\
\hline & Standard deviation & & 2.54 & 21.47 & 133.58 & 85.31 & 60.75 & 2.93 & & \\
\hline & Minimum & & $92.00 \%$ & 12.00 & 20.00 & 0.00 & 8.00 & 1.00 & & \\
\hline & Median & & $96.45 \%$ & 37.00 & 78.00 & 43.00 & 32.00 & 3.00 & & \\
\hline & Maximum & & $100.00 \%$ & 79.50 & 607.00 & 358.00 & 249.00 & 11.00 & & \\
\hline
\end{tabular}

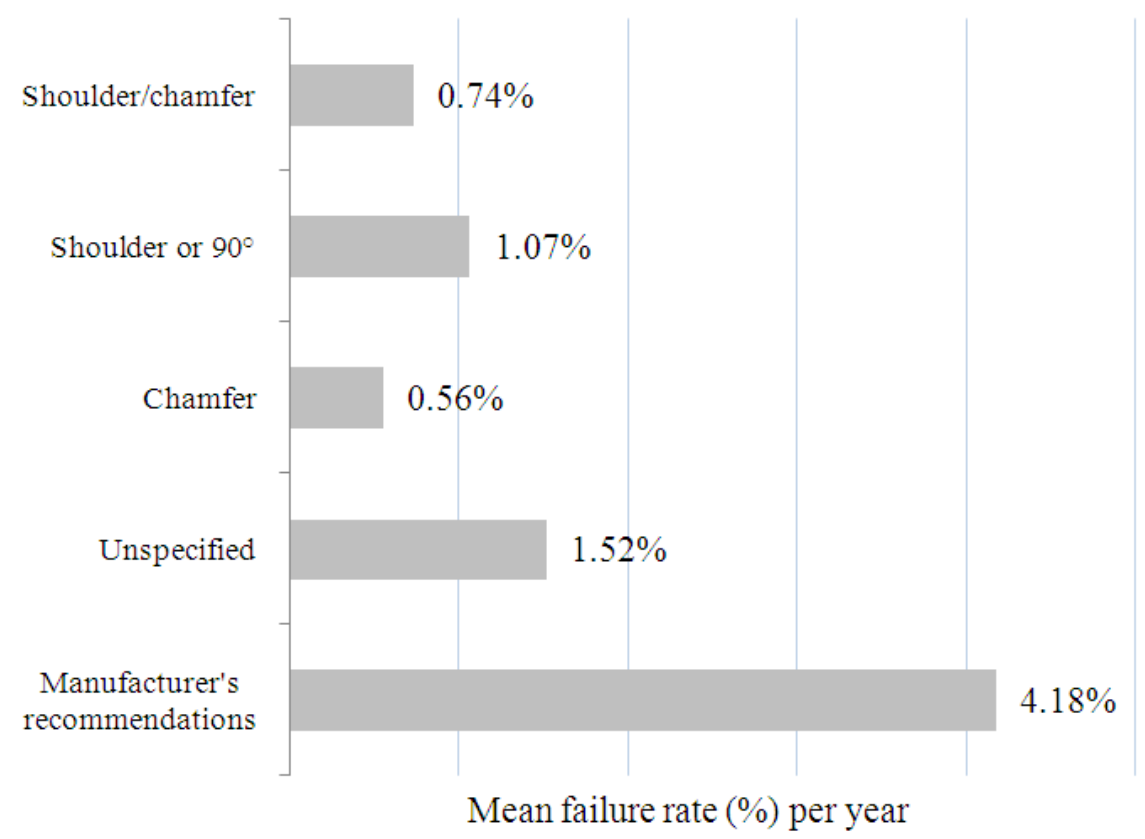

Fig. 1. Type of margin design Vs mean failure (\%) rate per year

\section{Total Occlusal Convergence}

Three articles reported the TOC used for the preparation of their crowns, however all three articles reported a range (Fradeani and Aquilano, 1997; Fradeani and Redemagni, 2002; Gehrt et al., 2013). These studies account for 373 crowns or $17.80 \%$ of the overall sample size. The associated failures account for 20 failures or $25 \%$ of overall failures. Sample size was considered to be too small because of the lack of information on TOC. Consequently, the relationship between TOC angle and survival could not be determined.

\section{Margin Design}

Information regarding margin design was given for all except two studies. The mean failure rate per year was grouped for the different margins specified (Fig. 1). There were ten studies that specified a shoulder or a $90^{\circ}$ shoulder design and the mean failure for this group was $1.07 \%$ per year. Two studies specified using only a chamfer design and the mean failure rate for this group was $0.56 \%$. The remaining studies reported a shoulder/chamfer design indicating the samples in the study had margin designs of both, did not specify their margin designs, or just cited manufacturer's recommendations. 


\section{Discussion}

In this review, a small number of short and long-term clinical studies were found in the literature, all reporting survival rates upwards of $92 \%$, which provides a positive indication of the performance of glass-ceramics. The inclusion and exclusion criteria of this study yielded 19 clinical studies for glass-ceramic single crowns of which three were retrospective studies (Fradeani and Aquilano, 1997; Sjogren et al., 1999; Valenti and Valenti, 2009) and remainder being prospective studies. However, none were randomised controlled trials.

The observation length is an important indication providing credible information on the survivability. Only six of the studies reported results for five years or more. Many clinical reviews reject short-term clinical studies (less than two or three years) as it could be argued that such short-term results are too short to make conclusive determinations regarding the survivability of a material. There is however, a scarcity of long-term clinical studies for glass-ceramic complete crowns. Similar reviews of all-ceramic crowns (Pjetursson et al., 2007; Wang et al., 2012) have a minimum follow-up period of at least 36 months to be included in the review. For this reason, in this review, another failure rate was calculated excluding studies with mean follow-up periods of less than 36 mon. This excluded seven of the studies and the failure rate was adjusted to $0.84 \%$. The five-year projection for the adjusted failure rate is $4.20 \%$.

Four studies reported $100 \%$ survivability in this revised review period (Marquardt and Strub, 2006; Taskonak and Sertgoz, 2006; Suputtamongkol et al., 2008; Fasbinder et al., 2010). However if short observation periods of less than 36 month was an exclusion criterion, three of the studies would have been excluded. Although the remaining study by (Marquardt and Strub, 2006) had a very small sample size of only 27 posterior crowns.

The two studies recording information from general practices that were not related to the authors were Sjogren et al. (1999) with $92 \%$ survivability and Mansour et al. (2008) with $93.9 \%$ survivability. They reported the lowest survivability percentages and were conducted for short periods (less than five years). Sjogren et al. (1999) reported seven fractured crowns that failed between one to four years. One crown loosened nine months after luting which was recemented and later fractured; one had a minor fracture; two had endodontic problems; and the others were unspecified but needed to be replaced. The study by (Mansour et al., 2008) was a retrospective study on general practices and did not specify the nature and exact site of each fracture. Notably, these two studies were also the same two studies that did not report margin designs.
This may be explained as the crowns were prepared by different clinicians in different general practices.

Reported failures included microleakage of cement, breakage in the resin cement, marginal chipping and occlusal and core fractures (Fradeani and Aquilano, 1997; Lehner et al., 1997; Sorensen et al., 1998; Fradeani and Redemagni, 2002; Gemalmaz and Ergin, 2002; Mansour et al., 2008; Valenti and Valenti, 2009; Reich and Schierz, 2013). Crack initiation in the luting agent due to mechanical failure is likely to initiate at the marginal area and possibly induce debonding of the restoration as it propagates (Bowley et al., 2012). Crack initiation can also occur below the occlusal surface of a posterior crown especially when the gap to be filled by the cement is substantial and resin shrinkage occurs upon curing (Kelly, 1999). Convergence angle is said to be an important factor in assisting the debonding of the restoration (Bowley et al., 2012). Furthermore, as debonding occurs in the luting agent, the flexural properties of the restoration material become a defining factor as masticatory forces are occlusally exerted (Sornsuwan and Swain, 2012). This may be an explanation for the failures initiated occlusally.

This study included leucite-reinforced and lithium disilicate glass-ceramics. Because of the limited number of studies on complete crowns in glassceramics, the type of material was disregarded when calculating fracture rates. Instead, the studies were pooled to give a more credible result for glass-ceramics in general. Further long-term well-designed studies are necessary in order to establish significant differences between both glass-ceramics in question.

Margin design influences the thickness and geometry of the restoration in the marginal area and can affect the glass-ceramic surface, introducing micro-cracks and flaws which is a possible explanation for marginal chipping and core fractures. In the meantime, only shoulders and chamfers were mentioned as margin designs for glass-ceramic clinical studies and bevel or knife-edge preparations were not utilised. Two articles used chamfers (Marquardt and Strub, 2006; Etman and Woolford, 2010), while the majority used shoulders or a combination of shoulders and chamfers. Chamfers were shown to have significantly weaker strength values than shoulder preparations (Doyle et al., 1990; Friedlander et al., 1990) but this report finds the failure rate of chamfer designs almost half that of shoulder designs. Because the chamfer group only had two studies, it is too small to be conclusive. Although Bernal et al. (1993) found that when etched and bonded with resin cement, chamfers should not be significantly different than shoulders. There is a lack of information regarding the abutment height and TOC angles recorded in the studies mentioned above. Three articles reported TOC but even then, only a range of values were recorded to 
encompass all the preparations. Studies measuring TOC angles in non-controlled environments show that while most clinicians acknowledge the need to have a small TOC, but the recommended TOC angles are not routinely being prepared (Goodacre et al., 2001). Prothero (1923) showed that retention at $10^{\circ}$ was only half of those at $5^{\circ}$. As the angle increases there is a higher chance of crown displacement when under masticatory forces. The displacement causes tensile stress in the margin and luting agent. The degree of displacement increases with increasing taper angles augmenting the chances of debonding (Bowley et al., 2012). No studies to the authors' knowledge have clinically tested the role of TOC angle with survival rates. Although discrepancies are acknowledged between recommendations and tapers produced in general practices, it may be that this discrepancy is often overlooked as literature promotes the role of the increasing strength of dental (resin) cements.

Furthermore, as many of the studies were prospective studies conducted in university settings under specialists' observations, the angle of convergence produced may not have depicted the kind of preparations produced by general practitioners in a general practice. Because the TOC plays a vital role in the retention and resistance of a crown, the resulting repercussions of significant deviations from the recommended values in clinical studies is still unknown.

The lack of information regarding the TOC and margin design in clinical studies can be attributed to the variability and complexity of measuring different parameters. There is an inherent lack of standardised methodology regarding the capturing of this information. In literature the TOC is commonly shown to be measured by projecting silhouettes of prepared dies (Ohm and Silness, 1978; Nordlander et al., 1988; Ayad et al., 2005), photocopies (Noonan and Goldfogel, 1991), photographs (Leempoel et al., 1987), or creating a digital cross sectioned image (Annerstedt et al., 1996; Oilo et al., 2003; Güth et al., 2013). Time consuming methods of measuring TOC can deter clinicians from accurately recording the TOC. This means the recording of design parameters for clinical studies is often neglected.

There is a multitude of variables that affect the survival percentages in clinical studies. The report by Anusavice (2012) highlighted the need for more specific information to be included in clinical studies regarding failures. The possibility for more information regarding the TOC and margin design could help correlate its role with the resulting etiology of failures.

The author's propose the implementation of a measuring system integrated into CAD software for data collection. This provides the potential for future clinical studies to include specific TOC and margin designs of each preparation; and also providing for future understanding of the effects of TOC and margin design on the survivability of complete crowns.

\section{Conclusion}

It was evident that the geometry of the initial tooth preparation plays a vital role in retention and resistance of single crown restorations. However, no clinical studies to date have focused on this topic. Although many studies report margin designs and even fewer report TOC angles, it was impossible from the information provided in these reports to ascertain their effects on the restorations clinical survivability.

Further studies need to be conducted to determine how TOC angles and margin design influences the survival rates of glass-ceramic complete crowns.

\section{Author's Contributions}

Janine Tiu, J. and Neil Waddell: Participated in study design, literature search and review and writing of the manuscript.

Basil Al-Amleh and Michael V. Swain: Participated in study design and writing of the manuscript.

\section{Ethics}

This article is original and contains unpublished materials. The corresponding author confirms that all of the other authors have read and approved the manuscript and no ethical issues involved.

\section{References}

Annerstedt, A., U. Engstrom, A. Hansson, T. Jansson and S. Karlsson et al., 1996. Axial wall convergence of full veneer crown preparations. Documented for dental students and general practitioners. Acta. Odontol. Scand., 54: 109-112. PMID: 8739142

Anusavice, K.J., 2012. Standardizing failure, success and survival decisions in clinical studies of ceramic and metal-ceramic fixed dental prostheses. Dent. Mater., 28: 102-111. DOI: 10.1016/j.dental.2011.09.012

Ayad, M.F., A.A. Maghrabi and S.F. Rosenstiel, 2005. Assessment of convergence angles of tooth preparations for complete crowns among dental students. J. Dent., 33: 633-638. DOI: $10.1016 /$ j.jdent.2004.12.008

Bernal, G., R.M. Jones, D.T. Brown, C.A. Munoz and C.J. Goodacre, 1993. The effect of finish line form and luting agent on the breaking strength of Dicor crowns. Int. J. Prosthodont., 6: 286-290. PMID: 8397698 
Bowley, J.F., I.P. Ichim, J.A. Kieser and M.V. Swain, 2012. FEA evaluation of the resistance form of a premolar crown. J. Prosthodont., 22: 304-12. DOI: $10.1111 /$ j.1532-849X.2012.00949.X

Doyle, M.G., C.J. Goodacre, C.A. Munoz and C.J. Andres, 1990. The effect of tooth preparation design on the breaking strength of Dicor crowns. Int. J. Prosthodont., 3: 327-340. PMID: 2088368

Eames, W.B., S.J. O'Neal, J. Monteiro, C. Miller and J.D. Roan Jr et al., 1978. Techniques to improve the seating of castings. J. Am. Dent. Assoc., 96: 432-437. PMID: 342584

El-Ebrashi, M.K., R.G. Craig and F.A. Peyton, 1969. Experimental stress analysis of dental restorations. IV. The concept of parallelism of axial walls. J. Prosthet. Dent., 22: 346-353. DOI: 10.1016/0022-3913(69)90196-6

Etman, M.K. and M.J. Woolford, 2010. Three-year clinical evaluation of two ceramic crown systems: A preliminary study. J. Prosthet. Dent., 103: 80-90. DOI: 103: 80-90. 10.1016/S0022-3913(10)60010-8

Fasbinder, D.J., J.B. Dennison, D. Heys and G. Neiva, 2010. A clinical evaluation of chairside lithium disilicate CAD/CAM crowns: A two-year report. J. Am. Dent. Assoc., 2: 10-14. PMID: 20516109

Fradeani, M. and A. Aquilano, 1997. Clinical experience with empress crowns. Int. J. Prosthodont., 10: 241-247. PMID: 9484056

Fradeani, M. and M. Redemagni, 2002. An 11-year clinical evaluation of leucite-reinforced glassceramic crowns: A retrospective study. Quintessence Int., 33: 503-510. PMID: 12165985

Friedlander, L.D., C.A. Munoz, C.J. Goodacre, M.G. Doyle and B.K. Moore, 1990. The effect of tooth preparation design on the breaking strength of dicor crowns. Int. J. Prosthodont., 3: 159-168. PMID: 2133383

Gavelis, J.R., J.D. Morency, E.D. Riley and R.B. Sozio, 1981. The effect of various finish line preparations on the marginal seal and occlusal seat of full crown preparations. J. Prosthet. Dent., 45: 138-145.

DOI: 10. 1016/0022-3913(81)90330-9

Gehrt, M., S. Wolfart, N. Rafai, S. Reich and D. Edelhoff, 2013. Clinical results of lithiumdisilicate crowns after up to 9 years of service. Clin. Oral. Investig., 17: 275-284.

DOI: $10.1007 / \mathrm{s} 00784-012-0700-\mathrm{x}$

Gemalmaz, D. and S. Ergin, 2002. Clinical evaluation of all-ceramic crowns. J. Prosthet. Dent., 87: 189-196. DOI: 10. 1067/mpr.2002. 120653

Goodacre, C.J., W.V. Campagni and S.A. Aquilino, 2001. Tooth preparations for complete crowns: An art form based on scientific principles. J. Prosthet. Dent., 85: 363-376. DOI: 10.1067/mpr.2001.114685

GPT, 2005. The glossary of prosthodontic terms. J. Prosthet. Dent., 94: 10-92.

DOI: $10.1016 /$ j.prosdent.2005.03.013
Güth, J.F., J. Wallbach, M. Stimmelmayr, W. Gernet, F. Beuer and D. Edelhoff, 2013. Computer-aided evaluation of preparations for CAD/CAM-fabricated all-ceramic crowns. Clin. Oral. Investig., 17: 1389-95. DOI: $10.1007 / \mathrm{s} 00784-012-0812-3$

Jorgensen, K.D., 1955. The relationship between retention and convergence angle in cemented veneer crowns. Acta. Odontol. Scand., 13: 35-40. PMID: 14398174

Kaufman, E.G., D.H. Coelho and L. Colin, 1961. Factors influencing the retention of cemented gold castings: The cementing medium. J. Prosthet. Dent., 11: 487-502.

DOI: 10. 1016/0022-3913(66)90152-1

Kelly, J.R., 1999. Clinically relevant approach to failure testing of all-ceramic restorations. J. Prosthet. Dent., 81: 652-661. DOI: 10.1016/S0022-3913(99)70103-4

Leempoel, P.J., P.L. Lemmens, P.A. Snoek and M.A. Van't Hof, 1987. The convergence angle of tooth preparations for complete crowns. J. Prosthet. Dent., 58: 414-416. DOI: 10.1016/0022-3913(87)90265-4

Lehner, C., S. Studer, U. Brodbeck and P. Scharer, 1997. Short-term results of IPS-Empress full-porcelain crowns. J. Prosthodont., 6: 20-30. DOI: 10.1111/j.1532-849X.1997.tb00061.x

Mack, P.J., 1980. A theoretical and clinical investigation into the taper achieved on crown and inlay preparations. J. Oral. Rehabil., 7: 255-265. DOI: $10.1111 /$ j.1365-2842.1980.tb00443.x

Malament, K.A., S.S. Socransky, V. Thompson and D. Rekow, 2003. Survival of glass-ceramic materials and involved clinical risk: Variables affecting long-term survival. Pract. Proced. Aesthet. Dent. PMID: 12680079

Mansour, Y.F., M.K. Al-Omiri, Y.S. Khader and A. AlWahadni, 2008. Clinical performance of IPS-Empress 2 ceramic crowns inserted by general dental practitioners. J. Contemp. Dent. Pract., 9: 9-16. PMID: 18473022

Marquardt, P. and J.R. Strub, 2006. Survival rates of IPS empress 2 all-ceramic crowns and fixed partial dentures: Results of a 5-year prospective clinical study. Quintessence Int., 37: 253-259. PMID: 16594356

McLean, J.W., J.R. Hubbard and M.I. Kedge, 1979. The Science and Art of Dental Ceramics. The nature of Dental Ceramics and Their Clinical Use. 1st Edn., Quintessence Publishing Company, IBSN-10: 0931386047, pp: 333.

Noonan, J.E. and M.H. Goldfogel, 1991. Convergence of the axial walls of full veneer crown preparations in a dental school environment. J. Prosthet. Dent., 66: 706-708. DOI: 10/1016/0022-3913(91)90457-8

Nordlander, J., D. Weir, W. Stoffer and S. Ochi, 1988. The taper of clinical preparations for fixed prosthodontics. J. Prosthet. Dent., 60: 148-151. DOI: 10.1016/0022-3913(88)90304-6 
Ohm, E. and J. Silness, 1978. The convergence angle in teeth prepared for artificial crowns. J. Oral Rehabil., 5: 371-375. DOI: 10.1111/j.1365-2842.1978.tb01256.x

Oilo, G., A. Tornquist, D. Durling and M. Andersson, 2003. All-ceramic crowns and preparation characteristics: A mathematic approach. Int. J. Prosthodont., 16: 301-306. PMID: 12854796

Owen, C.P., 1986. Retention and resistance in preparations for extracoronal restorations. Part II: Practical and clinical studies. J. Prosthet. Dent., 56: 148-153. DOI: 10.1016/0022-3913(86)90461-0

Pjetursson, B.E., I. Sailer, M. Zwahlen and C.H. Hammerle, 2007. A systematic review of the survival and complication rates of all-ceramic and metal-ceramic reconstructions after an observation period of at least 3 years. Part I: Single crowns. Clin. Oral Implants Res., 3: 73-85. DOI: 10.1111/j.1600-0501.2007.01467.x

Pjetursson, B.E., D. Thoma, R. Jung, M. Zwahlen and A. Zembic, 2012. A systematic review of the survival and complication rates of implant-supported Fixed Dental Prostheses (FDPs) after a mean observation period of at least 5 years. Clin. Oral Implants Res., 6: 22-38. DOI: 10.1111/j.1600-0501.2012.02546.x

Prothero, J.H., 1923. Prosthetic Dentistry. 1st Edn., Medico-Dental Publishing Co., Chicago, IL, ISBN-10: 1248894731, pp: 742.

Reich, S., S. Fischer, B. Sobotta, H.U. Klapper and S. Gozdowski, 2010. A preliminary study on the shortterm efficacy of chairside computer-aided design/computer-assisted manufacturing-generated posterior lithium disilicate crowns. Int. J. Prosthodont., 23: 214-216. PMID: 20552085

Reich, S. and O. Schierz, 2013. Chair-side generated posterior lithium disilicate crowns after 4 years. Clin. Oral. Investig., 17: 1765-72. DOI: $10.1007 / \mathrm{s} 00784-012-0868-0$

Rekow, E.D., N.R. Silva, P.G. Coelho, Y. Zhang, P. Guess and V.P. Thompson, 2011. Performance of dental ceramics: Challenges for improvements. J. Dent. Res., 90: 937-952. DOI: 10.1177/0022034510391795

Rosenstiel, S.F., M.F. Land and J. Fujimoto, 2006. Contemporary Fixed Prosthodontics. 1st Edn., Elsevier Health Sciences, ISBN-10: 0323028748, pp: 1130.

Schmitt, J., M. Wichmann, S. Holst and S. Reich, 2010. Restoring severely compromised anterior teeth with zirconia crowns and feather-edged margin preparations: A 3-year follow-up of a prospective clinical trial. Int. J. Prosthodont., 23: 107-109. PMID: 20305846

Sjogren, G., R. Lantto, A. Granberg, B.O. Sundstrom and A. Tillberg, 1999. Clinical examination of leucite-reinforced glass-ceramic crowns (Empress) in general practice: A retrospective study. Int. J. Prosthodont., 12: 122-128. PMID: 10371913
Sorensen, J.A., C. Choi, M.I. Fanuscu and W.T. Mito, 1998. IPS Empress crown system: three-year clinical trial results. J. Calif. Dent. Assoc., 26: 130-136. PMID: 9709648

Sornsuwan, T. and M.V. Swain, 2012. The effect of margin thickness, degree of convergence and bonding interlayer on the marginal failure of glasssimulated all-ceramic crowns. Acta Biomater., 8: 4426-4437. DOI: 10.1016/j.actbio.2012.08.006

Studer, S., C. Lehner and U. Brodbeck, 1998. Six-year results of leucite-reinforced glass ceramic crowns. Acta Med. Dent. Helv., 3: 218-225.

Suputtamongkol, K., K.J. Anusavice, C. Suchatlampong, P. Sithiamnuai and C. Tulapornchai, 2008. Clinical performance and wear characteristics of veneered lithia-disilicate-based ceramic crowns. Dent. Mater., 24: 667-673. DOI: 10.1016/j.dental.2007.06.033

Taskonak, B. and A. Sertgoz, 2006. Two-year clinical evaluation of lithia-disilicate-based all-ceramic crowns and fixed partial dentures. Dent. Mater., 22: 1008-1013. DOI: 10.1016/j.dental.2005.11.028

Toksavul, S. and M. Toman, 2007. A short-term clinical evaluation of IPS Empress 2 crowns. Int. J. Prosthodont., 20: 168-172. PMID: 17455438

Tylman, S.D., 1965. Theory and Practice of Crown and Bridge Prosthodontics. 5th Edn., Mosby, C.V., St. Louis, pp: 1249.

Valenti, M. and A. Valenti, 2009. Retrospective survival analysis of 261 lithium disilicate crowns in a private general practice. Quintessence Int., 40: 573-579. PMID: 19626232

Walton, J.N., F.M. Gardner and J.R. Agar, 1986. A survey of crown and fixed partial denture failures: Length of service and reasons for replacement. J. Prosthet. Dent., 56: 416-421. DOI: 10.1016/0022-3913(86)90379-3

Wang, X., D. Fan, M.V. Swain and K. Zhao, 2012. A systematic review of all-ceramic crowns: Clinical fracture rates in relation to restored tooth type. Int. J. Prosthodont., 25: 441-450. PMID: 22930765

Wiskott, H.W., J.I. Nicholls and U.C. Belser, 1996. The relationship between abutment taper and resistance of cemented crowns to dynamic loading. Int. J. Prosthodont., 9: 117-139. PMID: 863923 